\title{
Territórios violados, resistências e massacres de povos e pobres na história do brasil - mas a luta continua
}

\author{
The violent occupation of territories, resistences and \\ massacres of peoples alongside the impoverished in the \\ history of brazil - a story to be continued
}

\section{La ocupación violenta de territorios, resistencias y masacres de pueblos y de pobres en la história del brasil - pero la lucha continua}

\author{
(iD) Cláudio Jorge Moura de Castilho \\ Universidade Federal de Pernambuco - Recife - Pernambuco -Brasil \\ claudiocastilho44@gmail.com
}

Resumo: A reflexão sobre a violação de territórios e territorialidades das naturezas natural e humana no processo de expansão no tempo-espaço do capitalismo perverso que visa ao atendimento, preponderante, dos seus interesses econômicos, foi de grande relevância para reforçar o papel das classes dominadas e oprimidas na história do Brasil. O materialismo histórico e dialético, com o suporte de métodos de procedimentos relativos a uma análise livre do conteúdo de parte da bibliografia acerca da problemática ora tratada e do destaque de palavras ditas por sujeitos que pronunciam o seu mundo, através da sua prática existencial, para entendê-lo melhor no sentido de mudá-lo, foi de fundamental importância para a concretização da nossa reflexão. O principal resultado ao qual se chegou refere-se à explicitação do fato de que, não obstante os fortes imperativos da racionalidade técnico-instrumental do capitalismo que viola os territórios que Ihes interessa, nunca deixa de haver reações das classes dominadas a tais ações.

Palavras-chave: Capitalismo. História. Dialética. Território Usado. 
Abstract: The reflection on the violation of territories and territorialities of the natural and human natures in the process of the expansion, in space and time, of the unrelenting needs of capitalism to serve its own economic interests, was fundamental for reinforcing the role of dominated and oppressed classes in Brazil's history. The historical and dialectical materialism approach, supported by procedures relevant to the free analysis of the content in the bibliographical dimension related to this issue was the emphasizing of words actually spoken by the subjects who pronounce their world, exposing existential practices that serve to understand the world in the sense of changing it, was important for carring out our reflection. The main result achieved by the study refers to the exposure of the fact that, in spite of the hideous strength of the techno-instrumental rationality of capitalism, resulting in the violation of the territories that are the objects of its speculation, the reactions of the dominated socioeconomic strata of society will never cease to exist.

Keywords: Capitalism. History. Dialectics. Territory in Use.

Resumen: La reflexión sobre la ocupación violenta de territorios y territorialidades de las naturalezas natural y humana en el proceso de expansión en el espacio-tiempo del capitalismo perverso, que vigila de manera preponderante sus intereses económicos, fue de grande relevancia para reforzar el papel de las clases dominadas y oprimidas en la historia de Brasil. El materialismo histórico y dialéctico, con el soporte metodológico de los procedimientos relativos al análisis libre del contenido de la parte bibliográfica acerca de la problemática y destacando las palabras usadas por los sujetos para nombrar su mundo, para entenderlo mejor, en el sentido del cambio, fue de fundamental importancia para la realización de nuestra reflexión. El principal resultado al que se llegó se refiere a la explicitación del hecho de que, no obstante los fuertes imperativos de la racionalidad técnico--instrumental del capitalismo que violenta los territorios que le interesa, nunca deja de haber reacciones de las clases dominadas a tales acciones.

Palabras clave: Capitalismo. Historia. Dialéctica. Territorio Usado. 
Territórios violados, resistências e massacres de povos e pobres na história...

\section{Introdução}

O presente artigo possui como objetivo principal retomar a ideia de que, no âmbito do acontecer histórico do capitalismo no seu tempo-espaço, a natureza natural e a natureza histórica - a dos territórios e a das territorialidades construídos pelas classes dominadas e oprimidas - sempre foram alvo de uma violação brutal com vistas à geração de riquezas.

A ideia de violação de territórios fundamenta-se, principalmente, na práxis realizada permanentemente no âmbito dos contextos das atividades de comunicação, segundo pressupostos teórico-metodológicos de Freire (1977), desenvolvidas pelo grupo de pesquisa Movimentos Sociais e Espaço Urbano (MSEU) junto a experiências de mobilização e movimentos sociais em Recife.

A despeito da história oficial ter demonstrado que, durante os quinhentos anos do Brasil, o território nacional foi construído de maneira pacífica e harmônica visando à formação de um país política e economicamente forte, com a participação de heróis sempre oriundos das classes dominantes - senhores, nobres, comerciantes e industriais dentre outros - desbravando o território, a história real demonstrou o contrário.

Pela sua própria natureza do capitalismo, o processo de formação e construção do território brasileiro, por outro lado, longe de ter sido pacífico e harmônico na perspectiva do progresso contínuo, foi permeado por uma série de contradições que sempre suscitaram tensões e conflitos da parte das classes dominadas e oprimidas. Na verdade, o que as classes dominantes desejaram, através da formulação e do uso do discurso fundado, preponderantemente, no caráter pacífico e harmônico de construção territorial, era fazer valer e manter no curso da história os seus interesses de classe.

Tanto que, sempre quando pessoas e grupos sociais das classes dominadas e oprimidas levantaram-se a fim de resistirem contra os processos de violação - invasão, destruição e subordinação aos 
Territórios violados, resistências e massacres de povos e pobres na história...

interesses capitalistas - dos seus territórios e das suas territorialidades, eram profundamente criminalizados, massacrados e, às vezes, reduzidos a pó; não obstante terem havido momentos em que eles conseguiram conquistas fundamentais à sua existência, muito embora os responsáveis por tais conquistas tenham sido retaliados pelos interesses hegemônicos.

Atualmente, no âmbito de um processo de retomada de ideias e práticas obscurantistas, as classes dominadas e oprimidas voltam a ser alvo de frequentes ameaças as quais se têm traduzido na retirada de direitos e, mesmo, na violação dos seus territórios e das suas territorialidades construídos com muita luta social e resistência. Daí a relevância de se continuar do lado destas classes sociais, escutando-as e destacando a sua palavra a fim de que elas, em dizendo a sua palavra, fortaleçam-se neste contexto tão adverso à sua existência, fazendo valer o seu papel também importante na história do Brasil.

O método de abordagem pelo qual se optou para a realização da discussão ora estabelecida acha-se representado pelo materialismo histórico e dialético, mediante o qual, partindo-se da história como um processo de movimento permanente do Mundo em algum sentido (a concretização dos interesses da expansão do capitalismo), considerou-se as contradições inerentes a este processo (as reações das classes dominadas e oprimidas), suscitando o estabelecimento de conflitos que podem rever e reverter os rumos do projeto de uso do território em vigência (outras possibilidades de Mundo).

Como métodos de procedimentos, lançou-se mão de uma análise livre do conteúdo de reflexões teóricas acerca da problemática ora focada, bem como da reunião de informações obtidas sobre experiências de reflexão e reação aos imperativos do capitalismo perverso, junto aos movimentos sociais dos quais o autor deste escrito se aproximou durante a sua carreira acadêmica.

Na perspectiva supracolocada, este artigo está estruturado de maneira a abordar o sentido dos cerca dos 520 anos de violação 
Territórios violados, resistências e massacres de povos e pobres na história...

de territórios de maneira mais intensa (primeira seção); a negação, o massacre e a criminalização das experiências de reação social (segunda seção); e a necessidade de se continuar a luta com base no aprendizado das experiências acontecidas, através de uma mobilização contínua movida pela esperança de que outro Mundo é possível (terceira seção).

\section{Quinhentos e vinte anos de violação de territórios de maneira mais intensa}

Partindo da hipótese de que, há cerca de 520 anos, o processo de imposição das relações capitalistas de produção-circulação-consumo no Brasil foi, na verdade, uma experiência, mascarada pelas fábulas do progresso/desenvolvimento, de violação de territórios e territorialidades que desrespeitou tudo o que encontrava em seu caminho, mas que, simultaneamente, tal processo não aconteceu de maneira linear; deseja-se ressaltar que, no seio do próprio movimento histórico, sempre se tem gestado, por parte das classes sociais dominadas e oprimidas, processos contraditórios de reação aos imperativos perversos do capitalismo.

Com efeito, os agentes da mundialização - hoje definida como globalização - têm-se expandido nos diversos territórios do Mundo destruindo tudo o que neles encontravam, transformando-os em mercadorias para gerar riquezas. Neste sentido, acentuou Moraes (1997), os territórios sempre foram considerados como "áreas vazias" a serem continuamente preenchidas como se fossem tábula rasa.

A este respeito, mutatis mutandis, fundamentando-se em uma preocupação semelhante, Freyre (1985) ressaltou que, no Nordeste do Brasil, isso se concretizou na medida em que a expansão extensiva e perversa da monocultura canavieira destruiu florestas, águas, solos, animais e pessoas às custas de um modelo de exploração avesso às preocupações de ordem ecológica. 
Territórios violados, resistências e massacres de povos e pobres na história...

De meados do século XIX a inícios do XX, com a colocação de ideias segundo as quais, em princípio, o progresso suporia uma evolução mas que esta evolução não corresponderia necessariamente ao progresso social na perspectiva de um equilíbrio instável, a geografia havia observado a consolidação de um processo de violação de territórios - não somente "vazios", mas também os ocupados há séculos - pelos interesses vinculados aos imperativos da racionalidade de uma forma de capitalismo que se fazia cada vez mais perversa.

Infelizmente esse fluxo das cidades para o exterior não se opera sem enfear o campo: não apenas os detritos de toda espécie preenchem o espaço intermediário compreendido entre as cidades e o campo, como também, algo ainda mais grave, a especulação apodera-se de locais encantadores da vizinhança; ela divide-se em lotes retangulares, cerca-os de muros uniformes, depois constrói às centenas e aos milhares casinhas pretenciosas. [...] À beira mar, as falésias mais pitorescas, as praias mais encantadoras também são em muitos lugares açambarcadas por proprietários invejosos ou por especuladores que apreciam as belezas da natureza à maneira dos cambistas avaliando um lingote de ouro. Nas regiões montanhosas frequentemente visitadas, o mesmo furor de apropriação apodera-se dos habitantes: as paisagens são recortadas em quadrados e vendidas ao comprador mais abondado; cada curiosidade natural, o rochedo, a gruta, a cascata, a fenda de um glaciar, tudo, até o som do eco, pode tornar-se propriedade particular. (RECLUS, [1866] 2010, p. 85-86)

Nota-se, assim, a preocupação do autor para com os problemas atinentes à expansão dos interesses especulativos em áreas do campo, do litoral e das montanhas, apropriando-se delas, e transformando-as em mercadorias a fim de engendrar lucros obtidos através da inserção desses espaços e de tudo o que eles continham no mercado. 
Territórios violados, resistências e massacres de povos e pobres na história...

Empreendedores apossam-se das cataratas, cercam-nas de tapumes para impedir os viajantes não-pagantes de contemplar o tumulto das águas, depois, à força de publicidades, transformam em belas moedas sonantes a luz que brinca nas gotículas rompidas e o sopro do vento que espalha no espaço echarpes de vapores. Porquanto a natureza é profanada por tantos especuladores precisamente por causa de sua beleza, não é surpreendente que em seus trabalhos de exploração os agricultores e os industriais negligenciem quanto a perguntarse se eles não contribuem para o enfeamento da terra. É certo que o "duro labor" preocupa-se muito pouco com o encanto do campo e com a harmonia das paisagens, desde que o solo produza colheitas abundantes; portanto seu machado ao acaso nos bosquetes, ele abate as árvores que o incomodam, mutila indignamente as outras e dá-lhes o aspecto de estacas ou vassouras. Vastas regiões, outrora belas de se ver e que se amava percorrer, foram inteiramente desonradas, e experimentase um sentimento de verdadeira repugnância ao observá-las. (RECLUS, [1866] 2010, p. 86-87)

Reconhecendo este processo de violação de territórios, a partir da destruição de territorialidades anteriormente construídas seja pela dinâmica da natureza natural seja pela da natureza histórica - como ações brutais, observa-se não somente o sentimento de perda de algo inerente a si mesmo enquanto ser humano - na medida em que, para o autor, o "Homem é a natureza adquirindo consciência de si mesma" (RECLUS, 2010, p. 13) - como, simultaneamente, a indignação diante dos resultados de tais ações.

Ao início do século XX, outro geógrafo francês também se ocupara, no âmbito do que hoje se considera questões ambientais, com problemas atinentes a desmatamentos, degradação de solos, extermínio de animais e seres humanos; tratando-se, assim, em sua complexidade, de ações de violação de territórios e territorialidades em função preponderantemente do dinheiro. 
Territórios violados, resistências e massacres de povos e pobres na história...

Devastação e pilhagens feitas pelos nômades Tuaregues no oásis cultivado, ou explotação imprevidente e irracional das plantas produtoras de borracha no Congo ou na Amazônia são fatos análogos à caça imoderada que tende ao extermínio de certas espécies - pássaros de aigrettes, animais de peles valiosas ou marfim. Ora, se refletirmos nisso, veremos que os fatos primitivos de destruição vegetal, de caça ou de pesca, sem implicar sempre tão graves e gerais conseqüências [sic], sem, com certeza, merecer julgamento tão severo, e mesmo poderem às vezes estarem associados a uma sábia economia da terra, tendem, todos, à retirada dos sêres [sic] vivos do nosso globo, para a reprodução dos quais o homem de maneira alguma cooperou; e todos, em seu princípio, são assassinos. (BRUNHES, [1909] 1962, p. 59)

O autor chamava a atenção para a necessidade de se rever as práticas de ocupação e uso do solo, da vegetação, das águas, bem como a natureza das relações sociais então vigentes, propondo o que denominou de sábia economia da terra. Associada a esta observação, nota-se a necessidade de considerar os limites com relação ao uso dos instrumentos de trabalho utilizados pelos homens e pelas mulheres visando à manutenção e, por conseguinte, à reprodução no tempo-espaço do seu poder sobre a Terra. Entretanto,

O poder e os meios de que o homem dispõe são limitados e o próprio homem se choca contra limites intransponíveis. Da mesma forma, nossa atividade na superfície da terra se acha detida por condições restritivas. Dentro de certos limites, pode variar seu jôgo [sic] e seus movimentos; não pode, porém, conseguir que êste [sic] quadro deixe de existir: muitas vêzes [sic], é possível modificá-lo, mas nunca suprimi-lo. (BRUNHES, [1909] 1962, p. 439)

Desse modo, o autor reconheceu as causas essenciais inerentes à questão ambiental articuladas à questão social conectadas entre si e em atividade, recolocando de maneira mais profunda a 
Territórios violados, resistências e massacres de povos e pobres na história...

necessidade do homem autoconscientizar-se de que necessitaria reaproximar-se da natureza através de uma postura mais humilde, dialógica e sábia.

Nunca se deve esquecer que os fatos de Geografia Humana não encontram sua explicação completa, nem seu único princípio de coordenação, nas causas geográficas sómente [sic]: o reflexo psicológico das causas geográficas sôbre o ser humano e, na medida dos seus próprios apetites, necessidades ou vontades, êste [sic] é bem o fator sutil e complexo que deve prevalecer em todo o estudo de Geografia Humana: o fator que permite distribuir e coordenar os fatos, com relação às causas naturais e com relação ao homem. Muitos geógrafos, depois de terem falado, não sem razão, da ação e reação das fôrças [sic] naturais e das fôrças humanas, perguntam com demasiado rigor e de forma muito abstrata: até que ponto se exerce a influência das fôrças naturais sôbre a atividade humana e em que medida o homem reage em face destas fôrças? E não conviria adotar em seguida, como princípio de uma divisão científica geral, os dois têrmos [sic] antitéticos: ação da Natureza sôbre o homem e reação ou ação do homem sôbre a Natureza? Daí nasceram as expressões de Geografia Humana passiva ou estática e Geografia Humana ativa ou dinâmica. (BRUNHES, 1962, p. 440)

Buscando responder explicitamente à indagação acima colocada, o autor reconhecera, ao mesmo tempo, que os homens e as mulheres devem perceber que também constituem partes importantes da natureza, tal como o fizera Élisée Reclus.

O homem nunca é completamente passivo, ou, melhor dito, só é inteiramente passivo quando agentes do mundo físico lhe tiram a vida. Enquanto vive, êle [sic] age, reage; bebe, come, se estende em um ponto do globo para dormir, atos êstes em que é fácil reconhecer o gesto da sua própria participação nos fatos geográficos. (BRUNHES, [1909] 1962, p. 441) 
Territórios violados, resistências e massacres de povos e pobres na história...

Diante do exposto, portanto, observa-se que a geografia, desde os seus primórdios em meados da segunda metade do século $\mathrm{XIX}$, colocou-se como campo do conhecimento científico irrequieto que possuía uma visão complexa e dinâmica de mundo e que, por tal motivo, abriu caminhos interessantes para se pensar em "possibilidades" concretas a fim de enfrentar o grau exacerbado de violação da natureza pela introdução de novas técnicas que intermediavam as relações do homem com o seu meio existencial.

Se os homens e as mulheres não se autoconscientizarem-se de tal problema, os seus ambientes existenciais prejudicar-se-ão ainda mais, o que se reverberá sobre si mesmos, notadamente porque a resposta da natureza acontece de acordo com a postura das ações antrópico-antropogênicas com relação ao meio que the serve de suporte. E se tal postura não se dá de maneira sábia, mas exacerbadamente destruidora, a natureza pode "vingar-se".

Assim, tudo é para os homens, sôbre a superfície do nosso globo, trabalho de costume, de sã compreensão dos fatos físicos e de hábil adaptação a êstes últimos. Porém é preciso que a adaptação se opere prontamente, na hora oportuna percebida, preparada e conduzida por pesquisas científicas exatas. A vingança dos fatos físicos contrariados é tanto mais cruel quanto mais grandiosa e gloriosa tenha sido a conquista humana. (BRUNHES, [1909]1962, p. 443)

Apelando para o elemento psicológico, ressaltava-se a necessidade de mudança no âmbito da percepção teórica e prática com relação ao lidar com a sua própria natureza no sentido ao mesmo tempo de atingir à raiz de todo o problema, ou seja, o modelo consumista de sociedade que já se apontava no tempo em que tais reflexões foram realizadas.

Tratava-se, assim, de uma perspectiva de se buscar uma forma de reeducação do homem, talvez se aproximando do que se chama hoje educação ambiental; o que, aliás, geógrafos irreverentes como Elisée Reclus já havia colocado. Isso, para começar a 
Territórios violados, resistências e massacres de povos e pobres na história...

combater, pela explicação geográfica, os impactos causados pelo consumismo exacerbado.

De certo modo, é a mesma coisa forçar as condições naturais e exagerar a extensão de uma cultura, acrescendo excessivamente uma produção. Há no mundo um número limitado de bôcas e estômagos [sic] pronto para receber café ou vinho; não se saberia como modificar bruscamente nem seu número global, nem sua capacidade individual; é preciso ainda acrescentar que, para regular a necessidade de consumo, intervém, em primeiro lugar, o fator psicológico - gostos, moda, hábito, tradição - o verdadeiro senhor. (BRUNHES, 1962, p. 444)

Trata-se, portanto, de uma perspectiva de mundo em que a questão da violação de territórios esteve presente de maneira patente no momento em que se referiam à problemática do processo de ocupação - destrutiva - do solo em espaços na Terra, com finalidades preponderantemente produtivistas no âmbito de uma sociedade consumista em processo de crescimento e consolidação.

Sob a denominação geral de ocupação destrutiva deve-se agrupar tôda [sic] exploração da terra que tenda a extrair matérias-primas minerais, vegetais ou animais, sem intenção ou meios de restituição. Os homens que retiram de uma pedreira de molasso ou de mármore material para edificação de suas moradias, deslocam, sem intenção de substituí-los, materiais naturalmente engastados no solo. A pesca e a caça que não se ligam a uma criação, como a dos faisões ou dos salmões, constituem igualmente uma retirada da Natureza não compensada por esforços humanos. (BRUNHES, [1909] 1962, p. 290)

Mas, sabiamente, soube-se distinguir as formas de ocupação necessárias durante a existência humana daquelas efetivamente predatórias, ocorridas unicamente para a satisfação dos interes- 
Territórios violados, resistências e massacres de povos e pobres na história...

ses econômicos, inclusive chamando a atenção da sociedade de então para os impactos negativos desta ocupação violadora das bases de uma sociedade.

Entre as formas de ocupação destrutiva algumas possuem um caráter normal, metódico; as outras, pelo contrário, são caracterizadas por uma intensidade moderada, que as faz merecedoras da designação [...] rapina econômica ou, mais simplesmente, devastação. A economia destrutiva [...] é, em certo sentido, uma forma particular da coleta, mas que se exerce sôbre a Natureza com muito mais violência. Dêsse [sic] violento atentado pode resultar a miséria; é, então, a devastação caracterizada. (BRUNHES, [1909] 1962, p. 291)

A catástrofe do abandono de áreas após anos de exploração, deixando em seu rastro a miséria no espaço usufruído após o esgotamento das atividades decorrentes da mineração, a devastação das florestas e o extermínio de animais e homens - de negros e indígenas dizimados no processo de "colonização" do Novo Mundo - foi contrastada com a formação e execução de uma "reação amadurecida" de sociedades frente a tal processo destruidor. Isso demonstrou exemplos de que há condições de retomar as rédeas do processo contraditório de violação do seu território a fim de buscar uma solução mais adequada para a humanidade.

Nos últimos tempos tem havido uma grande preocupação sôbre todos êsses excessos destrutivos. Na Europa, nos Estados Unidos e no Canadá tomaram-se enérgicas medidas contra a devastação. Os Estados Unidos foram os primeiros a dar o exemplo criando uma espécie de museus naturais, os Parques Nacionais, que são verdadeiros conservatórios da vida vegetal e animal, assim como de tôdas as riquezas naturais. Foram criados parques nacionais no Canadá, na Argentina, na Alemanha, Suíça, França, etc. (BRUNHES, [1909] 1962, p. 300) 
Territórios violados, resistências e massacres de povos e pobres na história...

Com isso, o autor colocava o fato de que, contraditoriamente, o processo violador de territórios e territorialidades pode ser socialmente controlado através, por exemplo de uma legislação adequada, buscando ações mais construtivas em termos de produção territorial.

A economia destrutiva pode, portanto, ter um fim e uma significação construtivos. Ela destrói, é certo. O fato geográfico continua patente: essa forma de economia despoja incessantemente, em mil pontos, a superfície terrestre de suas riquezas, que não são nem serão nunca devolvidas. Porém, se tem construído, freqüentemente [sic], uma rapinagem, um desperdício, ela muitas vêzes tem proporcionado aos homens os materiais ou os meios mais poderosos para que tenham podido chegar ao presente estágio de incomparável desenvolvimento científico e técnico da vida civilizada à superfície de nosso globo. (BRUNHES, [1909] 1962, p. 326)

Enfim, achamo-nos aqui diante de outra grande contradição apontada pelo autor segundo a qual todo processo de produção destruidora dos territórios é acompanhado de ações de construção, o que, aliás, faz parte da natureza e história dos homens e das mulheres no mundo. Não havendo, portanto, como produzir espaço sem destruir a natureza, mas ter-se-ia que se fazer valer um compromisso em termos de responsabilidade dos homens e das mulheres para com um mundo a ser reconstruído de maneira ambientalmente mais consequente, ou seja, respeitando a sua diversidade a fim de manter a beleza da complexidade do Planeta. 
Territórios violados, resistências e massacres de povos e pobres na história...

\section{Anegação, o massacree a criminalização das experiências de reação social}

Fundamentando-se no "princípio de atividade", Bruhnes (1909, p. 257 apud CASTILHO, 2017b)', considerou o permanente movimento contraditório entre uma força que desagregaria/destruiria - a força louca do sol - e outra força que reintegraria/construiria/ reconstruiria - a força sábia da terra - dialeticamente, desordenando e reordenando o espaço. O que nos remete, por seu turno, à ideia de que, em vez de estável/certo, o Mundo é completamente instável/incerto, suscitando o sentimento de que é possível mudar o rumo das coisas.

Na medida em que, como colocado na seção anterior, em vez de ter sido controlada pela força sábia da terra, a lógica da racionalidade técnico-instrumental capitalista, norteada preponderantemente pela geração de riquezas a todo custo, continuou a imperar no processo civilizatório do Planeta, a violação dos territórios e das territorialidades não somente consolidou-se como, ao mesmo tempo, expandiu-se no tempo-espaço. Isso tem ameaçado, permanentemente, tanto os domínios de natureza que deveriam ser, como acentuou Ab' Sáber (2003), respeitados enquanto patrimônio histórico-paisagístico da humanidade, quanto os territórios humanos.

O extermínio e/ou a escravidão da natureza natural e da natureza histórica não deixaram de existir no tempo-espaço do Mundo; apenas foram ressignificados, hoje, sob o discurso de um futuro que, segundo Leroy (2010), nunca atinge à coletividade social. Entretanto, como a história é um processo contraditório, sempre se movimentando em algum sentido, foram-se esboçando diversas experiências de resistências da parte dos territórios violados.

Diferente do que, não isenta de intencionalidade alheia aos povos brasileiros das classes subalternas e oprimidas, a "história oficial nos tem contado", o processo de formação social-territorial

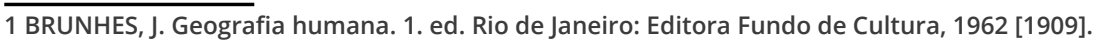


Territórios violados, resistências e massacres de povos e pobres na história...

do Brasil não aconteceu de maneira linear e os heróis ovacionados pelas classes dominantes são, na verdade, representantes de um projeto civilizatório perverso que permanece até aos nossos dias, violando territórios e territorialidades.

Muito ao contrário, a formação social-territorial do Brasil foi espiral e plena de conflitos inerentes à contradição da história a qual sempre se acha movimentando-se em algum sentido. Nesta perspectiva, as classes dominadas e oprimidas também tiveram os seus heróis e representantes das resistências ao projeto civilizatório vigente, os quais devem ser resgatados e reforçados por nós.

\begin{abstract}
Repetindo um conceito do prefaciador da obra de Max Beer História Geral do Socialismo - a respeito da história universal, podemos também afirmar, com relação à nossa, que "há muito se faz sentir a necessidade de uma história que não seja a glorificação das classes dirigentes". E traçar uma tal história é tudo quanto pensei fazer. [...] Quis mostrar [...] que também na nossa história os heróis e os grandes feitos não são heróis e feitos senão na medida em que acordam com os interesses das classes dirigentes, em cujo benefício se faz história oficial... [...] A Cabanada do Pará (1833-36,), a Balaiada no Maranhão (1838-41) e a Revolta Praieira de 1848 em Pernambuco [...] não passam, para a generalidade dos nossos historiadores, de fatos sem significação social e que exprimem apenas a explosão de "bestiais" sentimentos e paixões das massas. Isto principalmente com relação às duas primeiras". (PRADO JÚNIOR, 1985, p. 8)
\end{abstract}

Ademais, as aspirações buscadas por tais movimentos, dentre tantos outros que se fizeram presentes na história brasileira, bem como as experiências de territórios construídos com base em uma racionalidade orgânica, ou seja, contrária à racionalidade hegemônica, foram barbaramente negados e destruídos a exemplo dos inúmeros quilombos que se formaram no Brasil durante o período da escravidão oficial e com eles as suas lideranças mais conhecidas a exemplo de Zumbi e Dandara do Quilombo dos Palmares. 
Territórios violados, resistências e massacres de povos e pobres na história...

Da mesma maneira, durante o período da Primeira República ou República Velha ou República da Espada, o território Belo Monte foi completamente exterminado pela conhecida "Campanha de Canudos" e, com ele, sua liderança mais conhecida - Antônio Conselheiro; o que aconteceu sob discursos que colocavam esta experiência como algo, de uma certa feita, irrelevante, selvagem e, portanto, devendo ser negligenciado, sem apresentar a sua verdadeira natureza.

$\mathrm{Na}$ verdade, qualquer movimento procedente das classes dominadas e oprimidas sempre foi dizimado e, por conseguinte, alvo de destruição; muito embora elementos inerentes às suas respectivas territorialidades tenham permanecido no tempo como rugosidades, aguçando a dimensão psicológica da sociedade.

Sempre houve um sentimento de pavor e brutalidade das classes dominantes com relação às dominadas e oprimidas; e isto não somente devido ao medo da perda dos seus privilégios seculares, mas, ao mesmo tempo, ao ódio das primeiras classes sociais com relação às segundas, cujas raízes acham-se fincadas na escravidão, razão do forte distanciamento social que caracterizou a formação territorial do Brasil,

[...] agravando as oposições para acumular, debaixo da uniformidade étnico-cultural e da unidade nacional, tensões dissociativas de caráter traumático. Em consequência, as elites dirigentes, primeiro lusitanas, depois luso-brasileiras e, afinal, brasileiras, viveram sempre e vivem ainda sob o pavor pânico do alçamento das classes oprimidas. Boa expressão desse pavor pânico é a brutalidade repressiva contra qualquer insurgência e a predisposição autoritária do poder central, que não admite qualquer alteração da ordem vigente. (RIBEIRO, 2015, p. 20)

Este sentimento sempre foi tão forte que, vale reiterar, influiu em movimentos que tiveram significativo apoio de pessoas das classes dominantes que - com base em ideais do lluminismo europeu - imaginaram um Brasil diferente do projeto dominante 
Territórios violados, resistências e massacres de povos e pobres na história...

que persistia no tempo-espaço, com um pouco mais de liberdade muito embora a liberdade almejada não viesse, ainda, a atingir a coletividade dos brasileiros e das brasileiras.

Enfim, sempre quando algum movimento - protesto, revolta, motim, etc. - das classes dominadas e oprimidas cogitou a concessão, ainda que de maneira incipiente, de direitos para pessoas oriundas das classes dominadas e oprimidas, ele foi brutalmente reprimido, massacrado e criminalizado; o que, aliás, de acordo com Souza (2017), permanece até os dias que correm.

\section{A luta tem que continuar: aprendizado, movimento e esperança}

Enquanto houver capitalismo, as intencionalidades subjacentes à dinâmica social-territorial que o sustenta será norteada, preponderantemente, pelos imperativos da lógica da racionalidade técnico-instrumental capitalista perversa na medida em que este modo de produção-circulação-consumo é garantido pelos seus três princípios básicos: exploração do trabalho, crescimento econômico e geração de lucro. Trata-se, enfim, como escreveu Santos (2000), de um mundo perverso, que se apresenta como justo para todos e todas - fábula - mas que, ao mesmo tempo, pela sua própria dialeticidade, apresenta perspectivas de mudança.

Daí por que as críticas feitas, desde o século XIX e chegando ao início do século XX, por E. Reclus e J. Bruhnes sobre a referida racionalidade ainda se fazem pertinentes no século XXI. Com efeito, de acordo com Harvey (2013), o capitalismo tem-se consolidado cada vez mais no curso do seu acontecer histórico de expansão espacial-temporal há cerca de quinhentos anos, aproveitando-se, inclusive da dinâmica da destruição criativa para garantir a geração permanente de riquezas.

A história, nessa perspectiva, também nos ensina que a geração de riquezas visando ao lucro a todo custo vem sendo man- 
Territórios violados, resistências e massacres de povos e pobres na história...

tida, inclusive através da sofisticação do discurso "oficial" que se calca em perspectivas de processos de modernização (na cidade e no campo) que precisam substituir tradições (gêneros de vida, valores, etc.) locais, como alternativa fatal, e falsa, à concretização do desenvolvimento territorial. Andrade (1983) brindou-nos com um exemplo espetacular a este respeito, ao analisar criticamente o processo de mudança frente aos imperativos da modernização ocorrida por grandes obras de irrigação no Sertão do Nordeste brasileiro.

Contudo, em se tratando de um processo que se movimenta continuamente no tempo-espaço em algum sentido, numa dinâmica histórica contraditória e conflituosa, houve reações das classes sociais dominadas e oprimidas na tentativa, sempre árdua para elas, de conquistarem seus respectivos lugares na sociedade e no território brasileiros, negando bravamente as ameaças de terem seus territórios e suas territorialidades violados.

Concomitantemente, as práticas de lutas sociais inerentes às classes dominadas e oprimidas, conscientes de que o projeto de sociedade e território que lhes atinge não considera as suas histórias de vida, vêm sendo acionadas notadamente nos momentos em que elas se sentem ameaçadas pela cobiça que se acha impregnada em todas as ações vinculadas aos interesses hegemônicos.

Por outro lado, apesar da negação, do massacre e da criminalização das resistências das classes dominadas e oprimidas frente à violação dos seus territórios e das suas territorialidades, formas de conquistas inerentes às suas experiências de reação permaneceram no tempo-espaço em diversos lugares do mundo, ao nível da tecnosfera, combatendo as tentativas de destruí-las (Figura 1). 
Territórios violados, resistências e massacres de povos e pobres na história... Cláudio Jorge Moura de Castilho

Figura 1 - Imagens de projetos de uma cidade superposta sobre a cidade existente, violando as naturezas natural e histórica locais, em Recife-PE
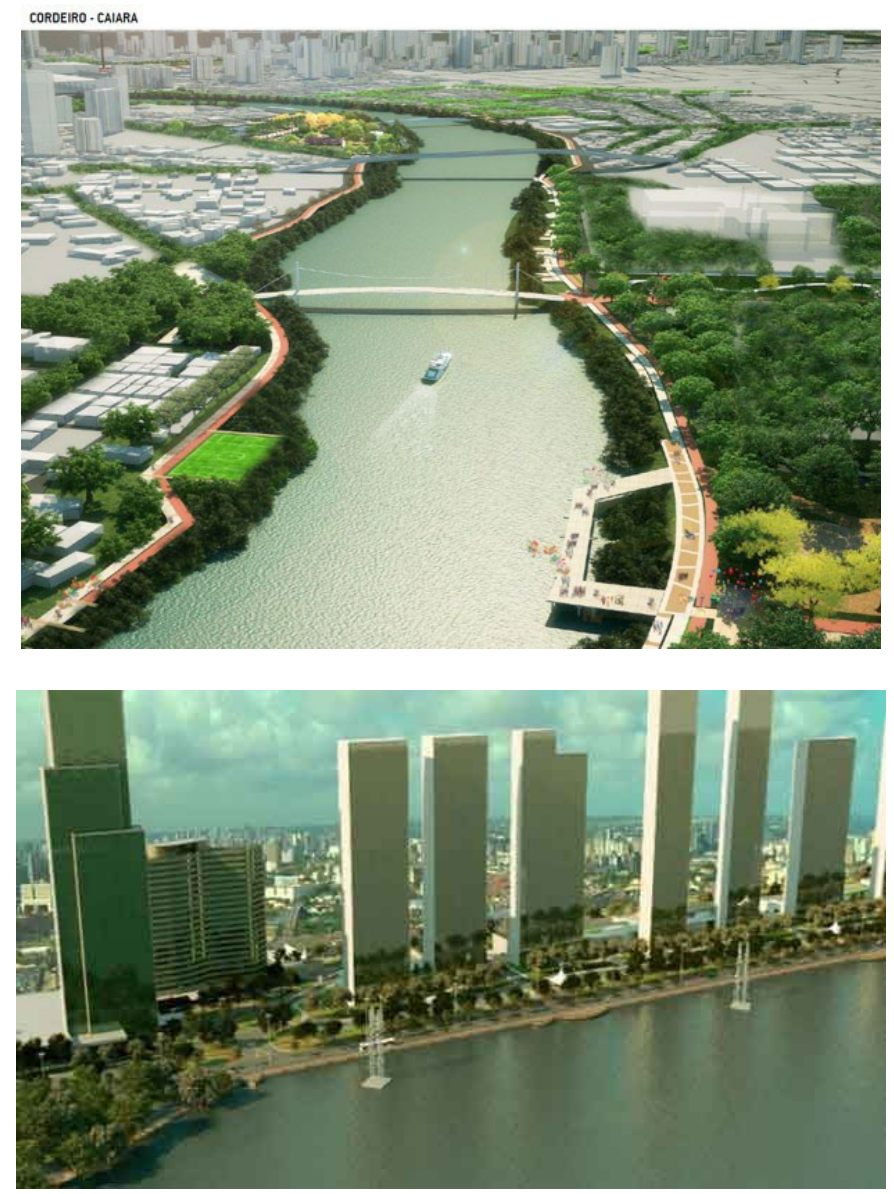

Fonte: Acervo pessoal do autor (2013).

Nota: Enquanto que na foto superior observa-se a imagem do projeto de implementação do Parque Capibaribe como um sistema resultante da articulação das áreas verdes da cidade, tendo como eixo principal o rio Capibaribe, negando os territórios brava e historicamente tecidos pelas classes dominadas e oprimidas que se acham localizadas em áreas ribeirinhas em torno das quais, por sua vez, coincidentemente, se acham setores das classes dominantes; na segunda, vê-se a imagem do Projeto Novo Recife o qual, na verdade, representa a continuidade histórica de um processo de uso do território que também nega tudo que está presente no seu sítio geográfico, mas que ainda não saiu do papel em função do movimento social \#OcupeEstelita que conseguiu atrapalhar o projeto, pelo menos até os dias que correm.

Com efeito, as classes dominantes sempre elaboraram e tentaram executar projetos de uso de territórios à sua própria imagem e semelhança, a fim de serem implementados, desconsiderando os interesses orgânicos das classes dominadas e oprimidas na medida em que estas, pelo menos em princípio, não lhes interessam de imediato. 
Territórios violados, resistências e massacres de povos e pobres na história...

Para isso, fazem uso de técnicas cada vez mais sofisticadas de violação de territórios, removendo os seus sujeitos e, por conseguinte, as suas respectivas territorialidades, com o que áreas históricas e populares têm sido violadas. Hoje, por exemplo, nas cidades, cada vez mais, populações de pobres e marginalizados são expulsas dos seus territórios visando à reocupação da sua área por ações urbano-urbanísticas - higienistas e gentrificadoras como imposição de uma arquitetura ultramoderna, inclusive impulsionadas, com o apoio do Estado pela e para a realização de grandes eventos (inter)nacionais - que, segundo ROLNIK (2015), atendem preponderantemente os interesses hegemônicos.

Da mesma maneira, ao nível da psicosfera, ratificando o elemento psicológico considerado por Reclus (2010) e Brunhes (1962), pelas falas de pessoas que vivem em territórios historicamente construídos por elas mesmas, escuta-se, após o acionamento do que existe no seu imaginário coletivo, um conjunto de palavras ditas e refletidas que nos remetem a uma história de muita resistência e luta sociais visando à conquista dos seus territórios e pelo reforço das suas territorialidades (Figura 2). 
Territórios violados, resistências e massacres de povos e pobres na história...

Cláudio Jorge Moura de Castilho

Figura 2 - Palavras ditas, em seu contexto cotidiano de existência, por moradores de territórios ameaçados de serem violados pelos interesses do Complexo Fundiário Imobiliário Comercial Financeiro (CFICF) durante atividades de mobilização para resistência, em Recife

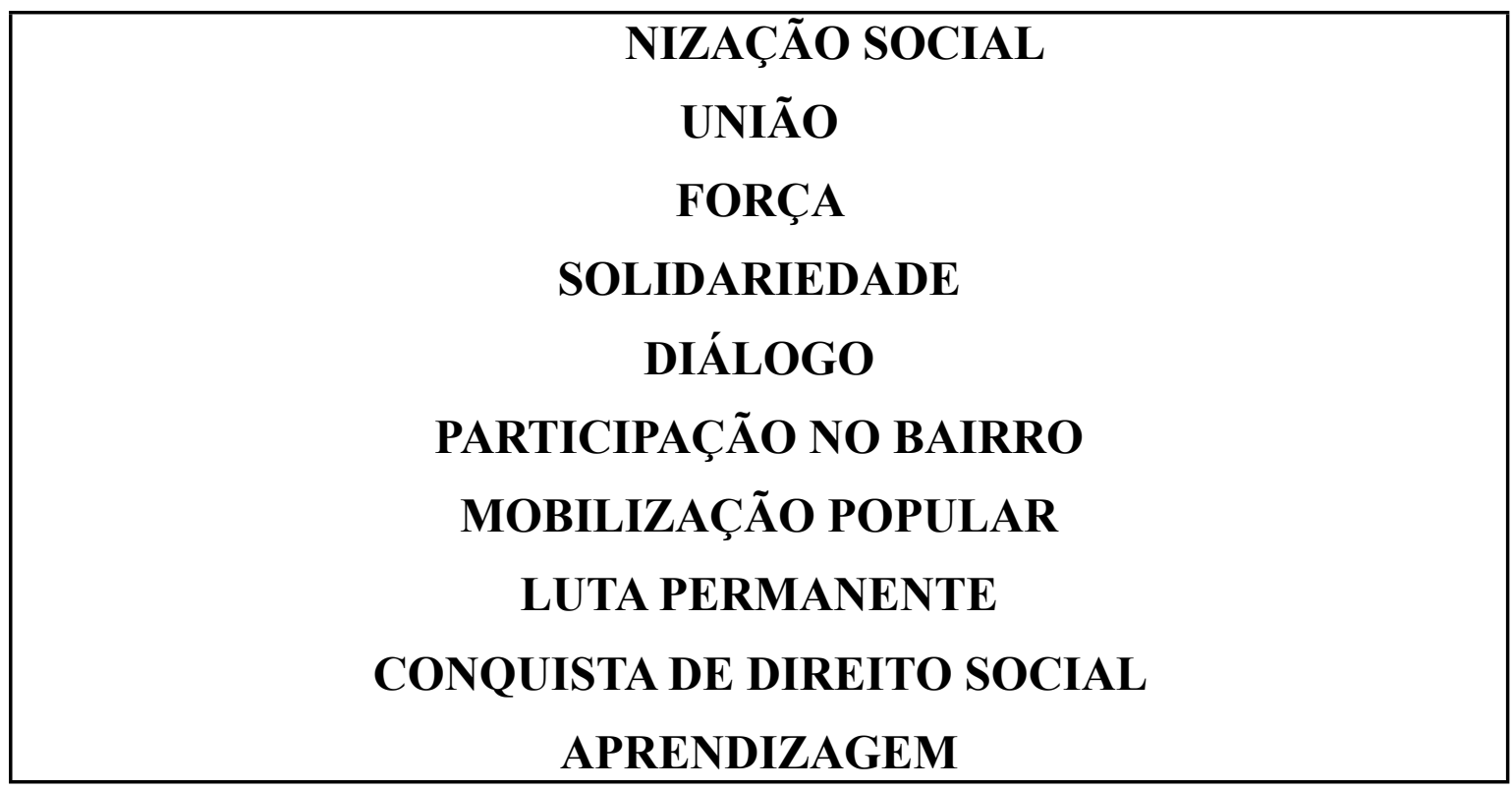

Fonte: Pesquisa de campo e atividades realizadas pelo autor deste escrito, durante mais de uma década de experiências de assessoria junto a movimentos sociais em Recife.

Nota: Ressalta-se que, de cima para baixo, acham-se listadas as palavras mais pronunciadas pelos moradores e pelas moradoras dos territórios ameaçados de serem violados.

No que se refere ao conjunto dessas palavras, como acentuava Freire (2019), o ato de dizê-las sobre o seu mundo, de pronunciar o seu mundo, constitui um passo fundamental no difícil processo de mudança social. Isto porque a mudança tem início quando o mundo passa a ser dito, discutido e questionado pelos seus sujeitos, os quais sempre buscam, segundo Santos (1987), serem mais em um Mundo tão adverso às suas aspirações; o que, segundo o mesmo autor, passa, antes de tudo, pela conquista da cidadania e, por sua vez, como observaram Schwarcz e Starling (2015), pela superação do secular estado de subcidadania em que vivem as classes dominadas e oprimidas no Brasil.

O espaço como, ao mesmo tempo, tecnosfera e psicosfera, constitui, portanto, uma totalidade complexa com a qual se pode aprender que o Mundo pode ser, efetivamente, diferente desde que o movimento contraditório inerente à sua dinâmica social-ter- 
Territórios violados, resistências e massacres de povos e pobres na história...

ritorial também continue a acontecer, desafiando o conjunto das adversidades à mudança que as classes dominadas e oprimidas almejam; bem como ressaltou Castilho (2017a), respeitando a complexidade ambiental inerente às especificidades da formação territorial da coletividade do povo brasileiro, e cumprindo, como escreveu Passet (2002), com o princípio iluminista da promessa de cuidado para com a natureza, natural e social.

É no âmbito do movimento supramencionado onde reside, portanto, a esperança não somente de se conquistar o bem-estar social para a totalidade dos territórios dos lugares do Mundo e valorizando as suas territorialidades; mas, ao mesmo tempo, é nele onde reside a oportunidade para se imaginar outros mundos possíveis, dentre os quais Acosta (2016), ao ter criticado as limitações do projeto social do bem-estar, discutiu profundamente a ideia do bem viver fundamentando-se em ensinamentos de povos autóctones do continente latino-americano.

\section{Conclusão}

No curso do acontecer histórico do capitalismo no Brasil, lugar em que este modo de produção-circulação-consumo se fez ainda mais perverso, os interesses das classes dominantes, norteados pela sua cobiça econômica, expandiram-se pelo Mundo, violando todos os territórios cobiçados para articulá-los aos seus propósitos.

Todavia, a história não é um processo linear, mas contraditório, suscitando movimentos de tensões e conflitos capazes de, quando fortes e conscientemente revistos pelos seus ativistas, reverter, pelo menos em termos de potencialidade, a violação dos territórios e das territorialidades historicamente construídos pelas classes dominadas e oprimidas.

O medo de perder seus privilégios e o ódio secular das classes dominantes com relação às classes dominadas e oprimidas têm 
Territórios violados, resistências e massacres de povos e pobres na história...

norteado atitudes de negação, massacre e criminalização de tais movimentos, muito embora as reações destas últimas tenham continuado a acontecer. E o desfecho final deste processo só poderá ser efetivamente demonstrado pelo movimento permanente da História.

\section{Referências}

$A B^{\prime}$ SÁBER, A. Os domínios de natureza no Brasil: potencialidades paisagísticas. São Paulo: Ateliê Editorial, 2003.

ACOSTA, A. O bem viver: uma oportunidade para imaginar outros mundos. São Paulo: Autonomia Literária, Elefante, 2016.

ANDRADE, M. C. de. Tradição e mudança: a organização do espaço rural e urbano na área de irrigação do Submédio São Francisco. Rio de Janeiro: Zahar Editores, 1983. (Coleção Agricultura e Sociedade).

BRUNHES, J. Geografia humana. 1. ed. Rio de Janeiro: Editora Fundo de Cultura, 1962 [1909].

CASTILHO, C. J. M. de. Do (des)respeito à complexidade ambiental no processo de formação do território brasileiro. In: GALVíNCIO, J. D.; OLIVEIRA, V. S. de; SOUZA, W. M. de (Org.). Mudança climática, sociedade, cidade e meio ambiente. Recife: Editora UFPE, 2017a.

CASTILHO, C. J. M. de. Jean Brunhes: a atualidade de um geógrafo do início do século XX. Revista Movimentos Sociais e Dinâmicas Espaciais, Recife, v. 6, n. 1, p. 253-272, 2017b.

FREIRE, P. Pedagogia do oprimido. 67. ed. Rio de Janeiro: Paz \& Terra, 2019 [1967].

FREIRE, P. Extensão ou comunicação? 12. ed. Rio de Janeiro: Paz \& Terra, 1977. 
Territórios violados, resistências e massacres de povos e pobres na história...

FREYRE, G. Nordeste. Aspectos da influência da cana sobre a vida e a paisagem no Nordeste do Brasil. 5. ed. Recife: José Olympio Editora, 1985 [1933].

HARVEY, D. Limites do capital. São Paulo: Boitempo, 2013. LEROY, J. P. Territórios do futuro: educação, meio ambiente e ação coletiva. Rio de Janeiro: Lamparina, 2010.

MORAES, A. C. R. Meio ambiente e ciências humanas. São Paulo: Editora Hucitec, 1997.

PASSET, R. A ilusão neoliberal. Rio de Janeiro: São Paulo: Record, 2002.

PRADO JÚNIOR, C. Evolução política do Brasil: Colônia e Império. 14. ed. São Paulo: Brasiliense, 1985.

RAFFESTIN, C. Pour une géographie du pouvoir. Paris: Litec, 1980.

RECLUS, É. Do sentimento da natureza nas sociedades modernas. São Paulo: Expressão \& Arte: Editora Imaginário, 2010 [1866].

RIBEIRO, D. O povo brasileiro: a formação e o sentido do Brasil. 3. ed. São Paulo: Global, 2015.

ROLNIK, R. Guerra dos lugares: a colonização da terra e da moradia na era das finanças. São Paulo: Boitempo, 2015.

SANTOS, M. O espaço do cidadão. São Paulo: Nobel, 1987.

SANTOS, M. A natureza do espaço: Técnica e tempo; Razão e emoção. São Paulo: Hucitec, 1997.

SANTOS, M. Por uma outra globalização: do pensamento único à consciência universal. Rio de Janeiro: Record, 2000.

SCHWARCZ, L. M.; STARLING, H. Brasil: uma biografia. São Paulo: Companhia das Letras, 2015. 
Territórios violados, resistências e massacres de povos e pobres na história...

SOUZA, J. A elite do atraso: da escravidão à lava jato; um livro que analisa o pacto dos donos do poder para perpetuar uma sociedade cruel forjada na escravidão. Rio de Janeiro: Leya, 2017.

Cláudio Jorge Moura de Castilho - Possui graduação em Geografia pela Universidade Federal de Pernambuco, mestrado em Geografia (Geografia Humana) pela mesma Universidade e doutorado em Geografia, Urbanismo e Ordenamento do Território pela Universidade de Paris III, com bolsa integral por quatro anos concedida pela CAPES. Atualmente é professor na Universidade Federal de Pernambuco, em regime de dedicação exclusiva à docência e pesquisa. ORCID: http://orcid.org/0000-0003-3609-9914

Recebido para a publicação em 5 de fevereiro de 2020 Aceito para a publicação em 4 de abril de 2020 Publicado em 5 de maio de 2020 